\title{
Infecciones asociadas a diálisis peritoneal en el paciente pediátrico: diagnóstico y tratamiento
}

\author{
M. Carolina Rivacoba, M. Luisa Ceballos y Paulina Coria
}

\section{Peritoneal dialysis-related infections in pediatric patients: diagnosis and treatment review}

Peritoneal dialysis-related infections are the main complication in pediatric patients undergoing this renal replacement therapy, associating a high rate of morbidity, generating also a decreasing survival of the peritoneal membrane and worsening the patient outcome. We describe the recommended diagnostic and therapeutic modalities to treat dialysis-related in children.

Key words: Peritoneal dialysis, peritonitis, tunnel catheter infection, exit site infection.

Palabras clave: Diálisis peritonal, peritonitis, tunelitis, infección de sitio de salida.

\section{Introducción}

$\mathrm{L}$ a diálisis peritoneal (DP) crónica sigue siendo la modalidad dialítica más frecuentemente utilizada para el manejo de los niños con enfermedad renal crónica terminal; sin embargo, esta terapia no está exenta de complicaciones. Dentro de éstas, las complicaciones infecciosas constituyen la causa más significativa de morbilidad en niños sometidos a diálisis ${ }^{1}$. Representan la primera causa de hospitalización y la segunda causa de mortalidad, alcanzando 5 a $10 \%$ del total de pacientes con peritonitis ${ }^{2}$. Esta infección puede tener un gran impacto a corto y largo plazo, disminuyendo el tiempo de vida útil y función de la membrana peritoneal (MP), lo que representa uno de los principales motivos de transferencia a hemodiálisis (HD) ${ }^{3}$. Además, ante episodios repetidos, puede producirse una esclerosis del peritoneo, lo que se asocia a malnutrición e incluso obstrucción intestinal ${ }^{4}$.

En relación a las complicaciones infecciosas de la DP se revisarán las peritonitis y las infecciones asociadas al catéter de diálisis peritoneal, las que incluyen: infección del sitio de salida y la tunelitis.

\section{Consideraciones sobre la membrana peritoneal}

La MP es la estructura que permite el intercambio dialítico en DP. Está compuesta por una monocapa de células mesoteliales, tejido conectivo, fibroblastos, macrófagos, vasos sanguíneos y linfáticos ${ }^{5}$ (Figura 1).

En pacientes sometidos a DP se han observado cambios en la integridad estructural de la MP. La constante exposición de la membrana a los fluidos de diálisis y los episodios de peritonitis reducen el volumen del glicocálix, causando a largo plazo, un acortamiento y disminución de la densidad de las microvellosidades de las células mesoteliales. Se describe también, el desprendimiento de las células mesoteliales de su membrana basal, con una denudación parcial o completa del mesotelio. Morfológicamente se observa un engrosamiento de la membrana basal, y una inducción de la transición epiteliomesenquimática en las células mesoteliales. Lo anterior conduce a fibrosis y esclerosis peritoneal, activación de los fibroblastos peritoneales, hialinización de los vasos sanguíneos y vasculopatía, determinando así la pérdida de la capacidad dialítica de la $\mathrm{MP}^{6}$.

\section{Catéter de diálisis peritoneal}

Para garantizar el éxito de la DP y disminuir el riesgo de infecciones asociadas, es fundamental la existencia de un catéter peritoneal funcional. Un catéter ideal debería proporcionar un flujo adecuado de líquido peritoneal (LP), sin filtraciones y con bajo riesgo de infección, lo que, pese a avances técnicos, aún no se ha logrado.

Los catéteres actualmente disponibles son de material poliuretano o silicona, y poseen distintos dispositivos de seguridad para evitar su desplazamiento, como: manguito o cuff de dacron y forma curvada (cuello de cisne). El catéter más frecuentemente usado en pediatría es el catéter curvo de Tenckhoff con dos cuff ${ }^{14,15}$.

Para la instalación del catéter, se realiza una incisión transversa de 2 a $3 \mathrm{~cm}$ de la línea media a izquierda o a derecha, lejos de ostomías, si las hubiese. Para evitar la oclusión precoz del catéter, se sugiere efectuar una
Universidad de Chile. Santiago, Chile.

Residente de Infectología Pediátrica (MCR).

Hospital Luis Calvo Mackenna. Santiago, Chile.

Servicio de Pediatría,

Unidad de Nefrología (MLC)

Unidad de Infectología (PC).

Conflictos de interés: Sin conflictos por declarar.

Recibido: 27 de agosto de 2017 Aceptado: 20 de febrero de 2018

Correspondencia a:

María Carolina Rivacoba Rojas carorivacoba@gmail.com 


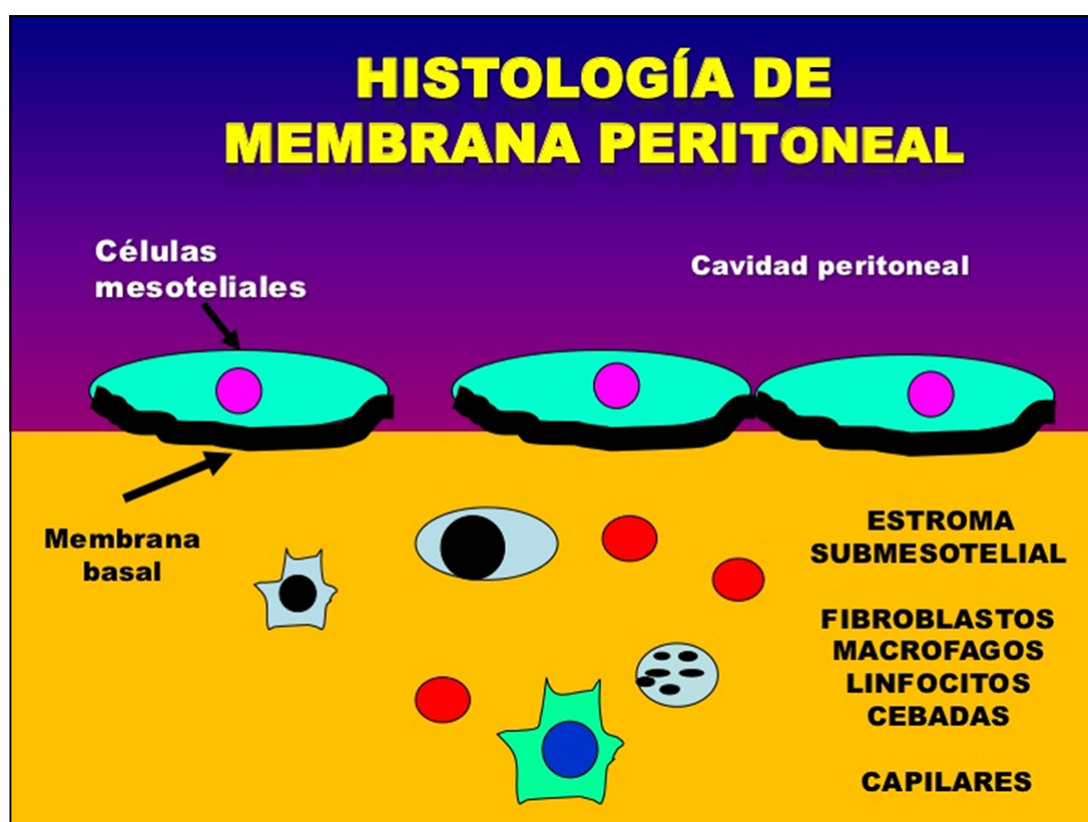

Figura 1. Membrana Peritoneal: se muestra esquemáticamente, la monocapa de células mesoteliales y el tejido conectivo subyacente: colágeno, mucopolisacáridos, capilares y células linfáticas.

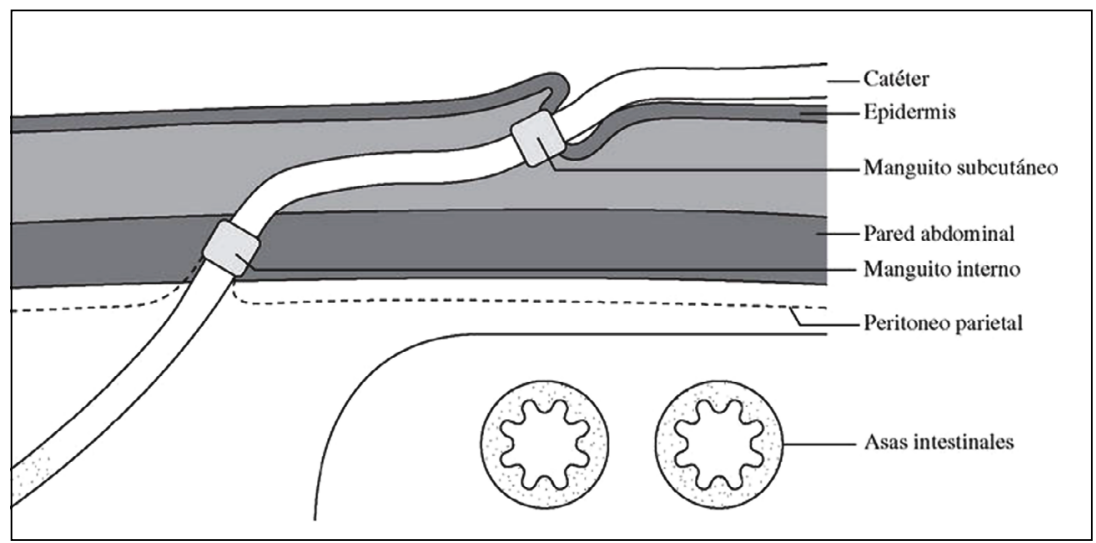

Figura 2. Visión esquemática de los componentes del catéter peritoneal y sus relaciones anatómicas.

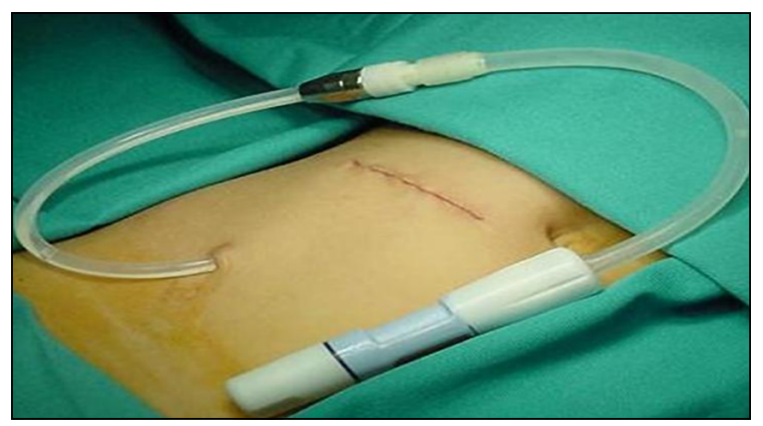

Figura 3. Catéter peritoneal y sus componentes: 1) orificio de salida (OS); 2) túnel subcutáneo; 3) Titanio 4) línea de transferencia; 5) Dispositivo de conexión. omentectomía subtotal. El cuff interno queda cubierto con el cierre de los planos muscular y aponeurótico, ocultándolo. Se confecciona un túnel subcutáneo para el extremo exterior, orientado hacia fosa ilíaca, procurando que el orificio de salida (OS) quede sobre la línea del pañal. El segundo cuff, queda a lo menos a $3 \mathrm{~cm}$ del OS. Se recomienda no fijar con puntos en el sitio de emergencia de catéter ni suturar la incisión, para evitar hematomas, granulomas e infecciones. Para diálisis crónica, se espera la cicatrización o maduración del túnel y del peritoneo, idealmente entre 14 y 21 días, para recién iniciar su uso. (Figura 2).

En la Figura 3, se muestran los componentes externos del catéter de DP.

\section{Epidemiología de las infecciones asociadas a diálisis peritoneal}

La prevalencia de infecciones asociadas a DP es de aproximadamente $30 \%$, según datos reportados por North American Pediatric Renal Trials and Collaborative Studies (NAPTRCS por su sigla en inglés), describiéndose el año 2011 una tasa de 0,79-0,41 episodios/paciente/año ${ }^{7}$.

En nuestro país, desconocemos su incidencia en niños, ya que no es un indicador de vigilancia obligatoria. Un estudio multicéntrico nacional, dio cuenta de una tasa de infecciones asociadas a DP de 0,67 episodios/paciente/ año ${ }^{4}$.

Respecto al momento de ocurrencia de infecciones en DP del total de eventos, se describe que aproximadamente $60 \%$ se presenta en los primeros seis meses post instalación del catéter de $\mathrm{PD}^{8}$.

\section{Factores de riesgo}

Se pueden categorizar como aquellos modificables y no modificables ${ }^{9}$ (Tabla 1). En niños se reconocen algunos factores de riesgo en particular: edad bajo los cinco años, volumen urinario bajo, infección asociada al orificio de salida (IOS), hipoalbuminemia, anemia y desnutrición ${ }^{10-13}$.

La infección puede producirse durante la inserción del catéter o por manipulación durante la conexión a la PD. Entre los factores de riesgo durante la inserción son importantes el quiebre de la técnica estéril, calidad de la técnica quirúrgica del cirujano, tamaño del catéter para evitar obstrucciones, instalación con línea de transferencia. El quiebre de la técnica estéril de conexión para la DP, suele ser la principal causa desencadenante de las infecciones asociadas a DP, por lo que un programa educativo estricto y la revisión de la técnica resultan fundamentales. 


\section{Patogénesis de las infecciones asociadas a diálisis peritoneal}

Las potenciales vías de infección descritas son ${ }^{16}$ :

- Intraluminal: una técnica de conexión o desconexión inadecuadas, con quiebre de la técnica estéril, permitirá el acceso de las bacterias a través del lumen del catéter.

- Periluminal: las bacterias presentes en la superficie de la piel entran en la cavidad peritoneal siguiendo la superficie externa del trayecto del catéter.

- Transmural: las bacterias de origen intestinal migran a través de la pared intestinal.

- Hematógena: una bacteriemia inicial puede producir una siembra en el peritoneo, el que puede estar más susceptible por la acción de la solución de diálisis y su $\mathrm{pH}$. Se ha reportado que las soluciones hipertónicas, inhiben la actividad bactericida local. Además, se han descrito bajas concentraciones de inmunoglobulina $\mathrm{G}$ peritoneal, lo que se asocia a un mayor riesgo de infección ${ }^{6}$.

\section{Tipos de infección asociados a diálisis peritoneal}

Las infecciones pueden ser localizadas como la infección en el sitio de salida (ISS) o tunelitis o las que comprometen el peritoneo o peritonitis.

\section{Peritonitis: diagnóstico}

El diagnóstico de peritonitis asociada a DP, se fundamenta en tres pilares: síntomas y signos clínicos, análisis citoquímico del LP y cultivo microbiológico, debiendo existir dos de los tres criterios que se detallan a continuación:

- Criterio clínico: Los síntomas sugerentes de infección peritoneal incluyen: dolor abdominal, náuseas, vómitos, anorexia, fiebre, constipación o diarrea, dificultad en el drenaje del LP, distensión abdominal. Entre los signos, el más importante a considerar es la presencia y demostración de un efluente turbio ${ }^{3}$.

- Criterio citoquímico de LP: recuento de leucocitos $\geq 100$ céls $/ \mathrm{mm}^{3}$ y recuento diferencial $>50 \%$ de polimorfonucleares ${ }^{3,16,17}$.

- Criterio microbiológico: Cultivo bacteriano positivo. Se detallará este punto en "Microbiología".

\section{Recomendaciones para la obtención de muestra del líquido peritoneal}

La obtención de una adecuada muestra de LP, para su análisis, es crucial para establecer el diagnóstico etiológico bacteriano de la peritonitis. Se deberá recolectar la muestra de LP tras la infusión de solución de diálisis (300 $\mathrm{ml} / \mathrm{m}^{2}$ ) con al menos $2 \mathrm{~h}$ de permanencia en el peritoneo y no más de $6 \mathrm{~h}$. Debe enviarse la bolsa de drenaje con el efluente al laboratorio (no enviar muestra en tubos) y la muestra debe procesarse dentro de $6 \mathrm{~h}$ como máximo. En caso de estimarse un mayor tiempo para esto, se recomienda la refrigeración del líquido a $4{ }^{\circ} \mathrm{C}^{18}$. Una vez obtenida la muestra debe ser centrifugada a $3.000 \mathrm{rpm}$ por $15 \mathrm{~min}$ en alícuotas de $50 \mathrm{ml}$ cada una, contando al menos con tres alícuotas. El sedimento obtenido, debe ser re-suspendido en 5-10 cc de solución salina fisiológica estéril ( $\mathrm{NaCl} 9 \%$ ) e inoculado en los medios de cultivos ${ }^{14}$.

Las técnicas microbiológicas disponibles son:

- Tinción de Gram: en pacientes con infección bacteriana la sensibilidad es baja, demostrándose presencia en aproximadamente $10 \%$ de los casos. Esta baja sensibilidad está relacionada con el número de bacterias presentes en el líquido peritoneal ${ }^{19}$. En pacientes en que se sospecha una infección fúngica alcanza al $30 \%{ }^{20}$.

- Cultivo en placas: agar sangre, agar chocolate, agar McConkey y medio de Sabouraud (incubar en $\mathrm{CO}_{2}$ a $\left.35^{\circ} \mathrm{C}\right)^{16}$.

- Siembra en frascos de hemocultivos: deberán llenarse dos frascos, idealmente aerobio y anaerobio, con 5 a 10 cc de LP, sin necesidad de centrifugación previa; luego incubar a $37^{\circ} \mathrm{C}$, por 5 a 7 días ${ }^{21}$.

- Biología molecular: la reacción de polimerasa en cadena (RPC) en tiempo real constituye una técnica complementaria, que permite aumentar la sensibilidad en la identificación de agentes, aumentando el rendimiento de los cultivos tradicionales, aún en pacientes que ya han iniciado tratamiento antimicrobiano. Permite además la reducción en el tiempo de identificación del agente ${ }^{9,16,22}$. Hasta ahora no existe una técnica específica de biología molecular para recomendar en forma universal.

De estas técnicas, la tinción de Gram y el cultivo en placas se deben realizar en todos los pacientes. Las

Tabla 1. Factores de riesgo asociados a infección en peritoneodiálisis

Factor de riesgo no modificable

Factor de riesgo modificable

Etnia

Sexo femenino

Malnutrición

Enfermedad pulmonar crónica

Enfermedad cardiovascular

Sobrepeso

Hipertensión arterial

Inmunosupresión

No uso de vitamina D

Anticuerpos anti hepatitis C

Factores psicosociales

Diabetes mellitus

Nefritis lúpica

Enfermedad renal secundaria a glomerulonefritis

Ausencia de función renal residual 
siembras en frascos de hemocultivos y el estudio de biología molecular son estudios complementarios, según la disponibilidad de cada centro.

\section{Microbiología}

La mayoría de las peritonitis asociadas a DP son bacterianas. Usualmente son ocasionadas por un microorganismo único, predominando las cocáceas grampositivas $(44 \%)^{1}$ : Staphylococcus aureus (21\%), Staphylococcus coagulasa negativa $(\mathrm{SCN})(22 \%)$ y bacterias del género Streptococcus ${ }^{1,3}$. Entre los bacilos gramnegativos destacan Escherichia coli y Pseudomonas aeruginosa. El espectro de microorganismos asociados a peritonitis en DP, varía geográficamente, al igual que la tasa de episodios con cultivo negativo ${ }^{18}$. En la literatura científica se describe entre 5 y $20 \%$ de cultivos sin identificación de agente, siendo lo recomendado una tasa de cultivos negativos no mayor a $10 \%{ }^{18,19}$. Por este motivo, se recomienda la revisión de la técnica de cultivo del laboratorio, si los resultados negativos superan el $20 \%{ }^{3,18}$.

\section{Tratamiento antimicrobiano de la peritonitis asociada a DP}

La terapia recomendada debe adaptarse a la epidemiología de cada institución conociendo los microorganismos involucrados y la susceptibilidad antibacteriana in vitro institucional ${ }^{13}$. La vía de administración de elección es intraperitoneal (IP), a menos que el paciente curse con una sepsis. La vía IP permite una inmediata biodisponibilidad del fármaco en el sitio de la infección, existiendo también una absorción vía sistémica, por lo que, si el paciente posee una diuresis residual, se debe considerar una toxicidad potencial según el antimicrobiano ${ }^{16,19,21}$. Se recomienda iniciar precozmente la terapia antibacteriana, una vez tomado los cultivos, con un esquema antimicrobiano de amplio espectro. Para la toma de decisión, debe tenerse presente, los patrones de susceptibilidad en infecciones previas tanto en el mismo paciente, como en el centro de referencia.

El esquema inicial debe cubrir bacterias grampositivas y negativas. Para ello se recomienda el uso de cefazolina, asociado a una cefalosporina anti-pseudomonas como ceftazidima o con aminoglucósido (amikacina o gentamicina). Las últimas guías clínicas pediátricas recomiendan iniciar con cefepime como monoterapia cuando se disponga de este antimicrobiano ${ }^{18}$; sin embargo, debe evaluarse su susceptibilidad en cada centro.

Las dosis de antimicrobianos y forma de administración se detallan en Tabla 2.

La susceptibilidad in vitro de las bacterias causantes debe guiar la terapia antimicrobiana, independientemente de la respuesta clínica inicial a la terapia empírica, por lo que se recomienda su ajuste según el antibiograma.

\section{Ajuste de esquema antimicrobiano según agente demostrado en el cultivo de LP}

Para cocáceas grampositivas: (Algoritmo 1)

- Las infecciones por SCN pueden ser secundarias a colonización del catéter o contaminación de la toma de la muestra, por lo que debe evaluarse con la clínica y el análisis citoquímico del LP. Desde el punto de vista clínico generalmente son leves y presentan respuesta rápida al tratamiento antimicrobiano.

- En contraste, $S$. aureus puede causar infección del catéter de PD, tunelitis o ISS y pueden estar asociadas a portación nasal de $S$. aureus. Del punto de vista clínico la sintomatología es más grave.

- Si se demuestra una cepa de $S$. aureus resistente a meticilina (SARM), la recomendación es ajustar terapia a clindamicina o vancomicina, con una duración total de tres semanas.

- En caso de Enterococcus sp o Streptococcus sp, la recomendación es ajustar a ampicilina. Se sugiere asociar con aminoglucósidos si la etiología es Enterococcus sp.; ante aislados resistentes a ampicilina debe utilizarse vancomicina intraperitoneal, en tanto que si existe resistencia a vancomicina la recomendación es uso de linezolid o daptomicina, por dos a tres semanas.

Para bacilos gramnegativos: (Algoritmo 2)

- Ante la sospecha de una enterobacteria (E. coli, Klebsiella sp, Enterobacter sp, otras) debe conocerse la prevalencia local de cepas productoras de $\beta$-lactamasas de espectro extendido (BLEE). Si la frecuencia es baja se puede utilizar una cefalosporina de primera o tercera generación, por dos semanas. En un medio con alta tasa de BLEE o si se aísla una cepa BLEE positiva, la terapia recomendada es un aminoglucósido, cefepime, un carbapenémico o una quinolona con actividad in vitro.

El tiempo de tratamiento recomendado para E. coli y Klebsiella sp no productora de BLEE, es de dos semanas; si es una cepa productora de BLEE será de tres semanas. En tanto para Enterobacter, Citrobacter, Serratia y Proteus se recomiendan 2 a 3 semanas.

- Ante sospecha de $P$. aeruginosa, debe evaluarse el perfil de susceptibilidad in vitro, dado el incremento de resistencia a ceftazidima en Chile y el mundo.

La resistencia a ciprofloxacina es un fuerte indicador de resistencia a múltiples antibacterianos y se ha asociado a un peor pronóstico. Ante infecciones por Pseudomonas spp. se recomienda un tratamiento antibacteriano bi-asociado de antimicrobianos con distinto mecanismo de acción y por un plazo mínimo tres semanas ${ }^{21}$. 


\begin{tabular}{|c|c|c|c|c|}
\hline \multirow[t]{2}{*}{ Tipo de antibiótico } & \multicolumn{2}{|c|}{ Terapia continua } & \multirow[t]{2}{*}{ Terapia intermitente } & \multirow[t]{2}{*}{ Vía de administración } \\
\hline & Dosis de carga & Dosis mantención & & \\
\hline $\begin{array}{c}\text { Aminoglucósidos } \\
\text { Gentamicina } \\
\text { Amikacina }\end{array}$ & $\begin{array}{c}8 \mathrm{mg} / \mathrm{L} \\
25 \mathrm{mg} / \mathrm{L}\end{array}$ & $\begin{array}{c}4 \mathrm{mg} / \mathrm{l} \\
12 \mathrm{mg} / \mathrm{l}\end{array}$ & $\begin{array}{l}\text { Anúrico: } 0,6 \mathrm{mg} / \mathrm{kg} \\
\text { No anúrico } 0,75 \mathrm{mg} / \mathrm{kg}\end{array}$ & Intraperitoneal \\
\hline $\begin{array}{l}\text { Cefalosporinas } \\
\text { Cefazolina } \\
\text { Cefepime } \\
\text { Cefotaxima } \\
\text { Ceftazidima }\end{array}$ & $\begin{array}{l}500 \mathrm{mg} / \mathrm{L} \\
500 \mathrm{mg} / \mathrm{L} \\
500 \mathrm{mg} / \mathrm{L} \\
500 \mathrm{mg} / \mathrm{L}\end{array}$ & $\begin{array}{l}125 \mathrm{mg} / \mathrm{L} \\
125 \mathrm{mg} / \mathrm{L} \\
250 \mathrm{mg} / \mathrm{L} \\
125 \mathrm{mg} / \mathrm{L}\end{array}$ & $\begin{array}{l}20 \mathrm{mg} / \mathrm{kg} \\
15 \mathrm{mg} / \mathrm{kg} \\
30 \mathrm{mg} / \mathrm{kg} \\
20 \mathrm{mg} / \mathrm{kg}\end{array}$ & Intraperitonetal \\
\hline $\begin{array}{l}\text { Glicopéptidos } \\
\text { Vancomicina }\end{array}$ & $1.000 \mathrm{mg} / \mathrm{L}$ & $25 \mathrm{mg} / \mathrm{L}$ & $\begin{array}{c}30 \mathrm{mg} / \mathrm{kg} \text { Siguientes dosis } 15 \mathrm{mg} / \mathrm{kg} \\
\text { cada 3-5 días }\end{array}$ & Intraperitoneal \\
\hline \multicolumn{5}{|l|}{ Penicilinas } \\
\hline $\begin{array}{l}\text { Quinolonas } \\
\quad \text { Ciprofloxacina }\end{array}$ & \multicolumn{3}{|c|}{ Quinolonas } & Intraperitoneal \\
\hline $\begin{array}{l}\text { Otros } \\
\text { Clindamicina }\end{array}$ & \multicolumn{2}{|c|}{ Otros } & & Intraperitoneal \\
\hline Linezolid & $\begin{array}{r}<5 \text { años } \\
5 \text { a } 11 \text { añ } \\
\text { Mayores } 1\end{array}$ & $\begin{array}{l}\mathrm{kg} / \mathrm{día} \mathrm{c/8} \mathrm{h} \\
\mathrm{g} / \mathrm{kg} \mathrm{c} / 12 \mathrm{~h} \\
00 \mathrm{mg} \mathrm{c} / 12 \mathrm{~h}\end{array}$ & & Vía oral \\
\hline Rifampicina & 10 a 20 mg/kg/ & 12 h máx. 600 mg & & Vía oral \\
\hline \multicolumn{5}{|l|}{ Antifúngicos } \\
\hline Caspofungina & $\begin{array}{r}\text { Carga } 70 \text { mg/m² (máx } \\
\text { días sigu }\end{array}$ & $\begin{array}{l}\text { :n día 1, luego } 50 \mathrm{mg} / \mathrm{m}^{2} \\
\text { náx } 50 \mathrm{mg} \text { ) }\end{array}$ & & Intravenoso \\
\hline
\end{tabular}

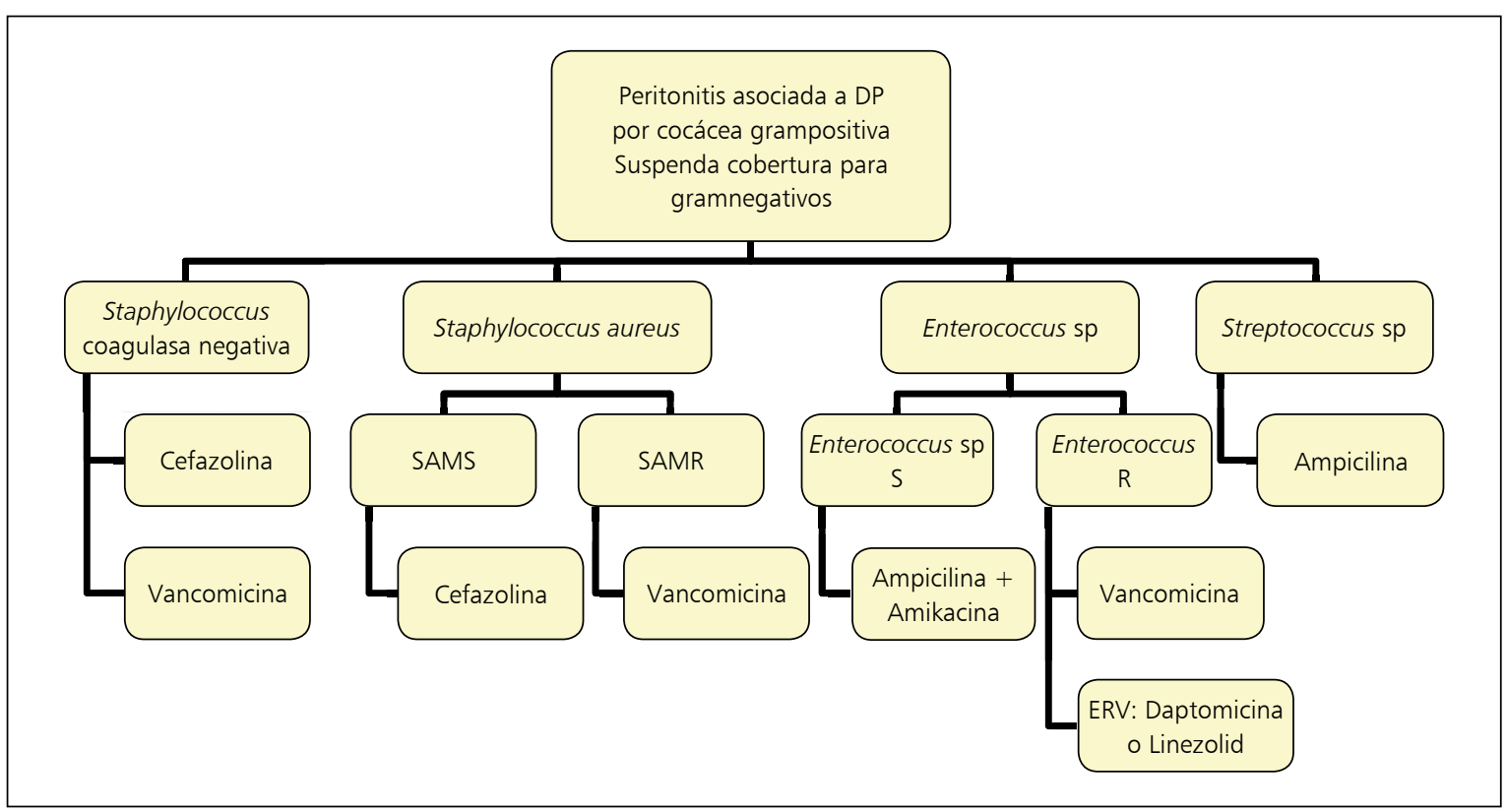

Algoritmo 1. Peritonitis asociada a DP por cocácea grampositiva. 


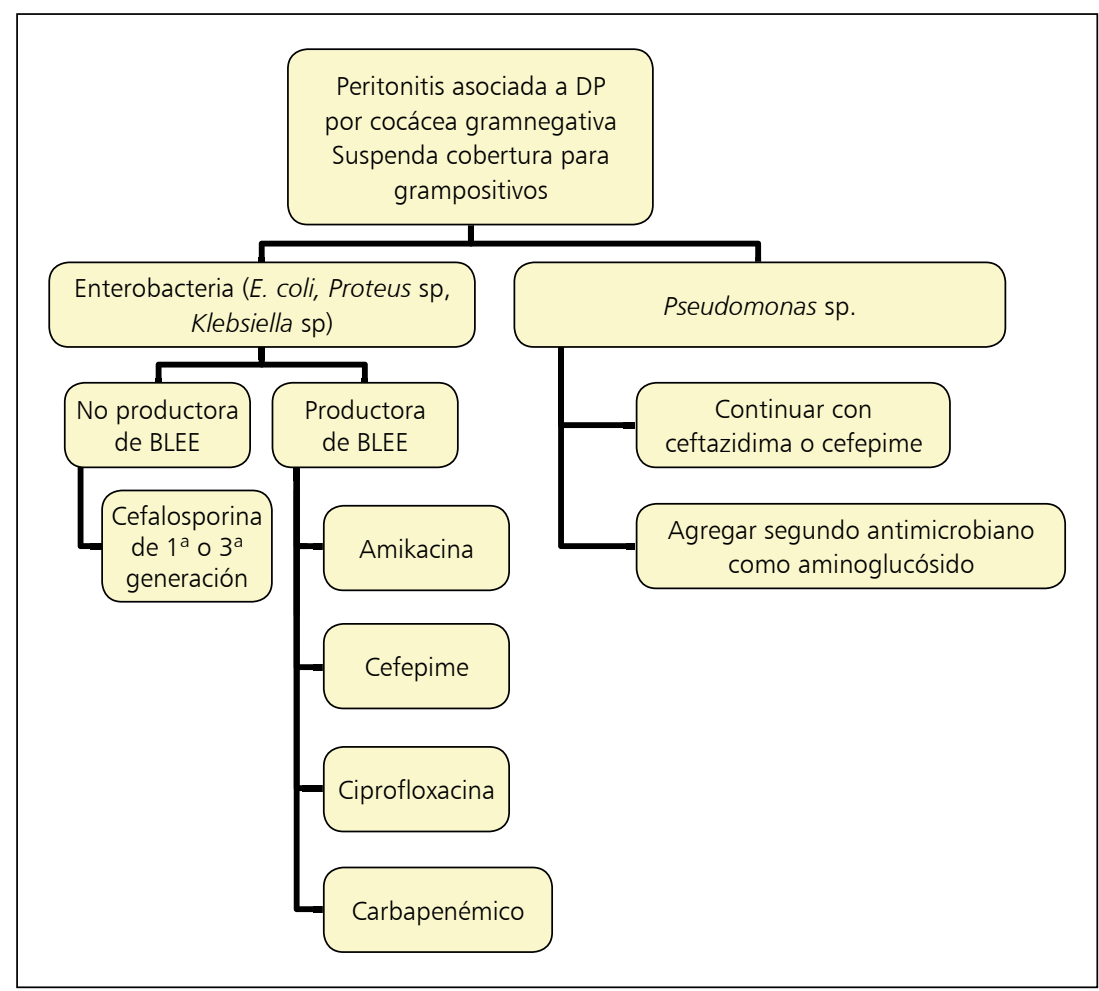

Algoritmo 2. Peritonitis asociada a DP por cocácea gramnegativa. BLEE: betalactamasa de espectro extendido.
- Si el cultivo está negativo a las $72 \mathrm{~h}$ se sugiere la suspensión del aminoglucósido.

- Si no hay mejoría del LP al quinto día de tratamiento, con cultivo negativo, se recomienda el retiro del catéter. Las probables causas de esta situación pueden ser: una peritonitis bacteriana con agente de crecimiento lento, baja carga bacteriana o una bacteria opsonizada, una peritonitis no bacteriana (viral o fúngica) o una peritonitis no infecciosa (química o eosinofílica).

Consideraciones respecto al uso de antimicrobianos por vía intraperitoneal ${ }^{16}$

- Si es posible se debe cambiar la modalidad de diálisis a una diálisis continua (puede ser manual o en la cicladora) con baños de permanencia de 4-6 h cada uno (terapia continua); en aquellos casos en que esto no sea posible, al menos un baño al día debe ser de larga permanencia para permitir una adecuada acción del antimicrobiano (terapia intermitente) ${ }^{16,18}$.

- La dosis de carga debe ser administrada en 4 a $6 \mathrm{~h}$ de permanencia.

- En pacientes que reciban vancomicina, se recomienda monitorizar sus concentraciones plasmáticas, cada 48 horas, para evitar la nefrotoxicidad y asegurar concentraciones terapéuticas. En general, el intervalo cada 4 a 5 días mantendría concentraciones adecuadas $(10-20 \mu \mathrm{g} / \mathrm{ml})$; si la concentración resulta $<10 \mu \mathrm{g} /$ $\mathrm{ml}$, se recomienda repetir la dosis ${ }^{21}$; si la concentración está $>20 \mu \mathrm{g} / \mathrm{ml}$ se recomienda mantener la monitorización cada 72 o $96 \mathrm{~h}$ hasta alcanzar un nivel terapéutico.

- Ante una infección por Stenotrophomonas maltophilia se recomienda tratamiento con cotrimoxazol por período de tres semanas.

Para peritonitis con cultivos negativos: (Algoritmo 3)

- Si el cultivo está negativo a las $72 \mathrm{~h}$, con mejoría de síntomas y signos, se sugiere mantener la terapia inicial con cefazolina asociado a ceftazidima o con cefepime, por dos semanas.

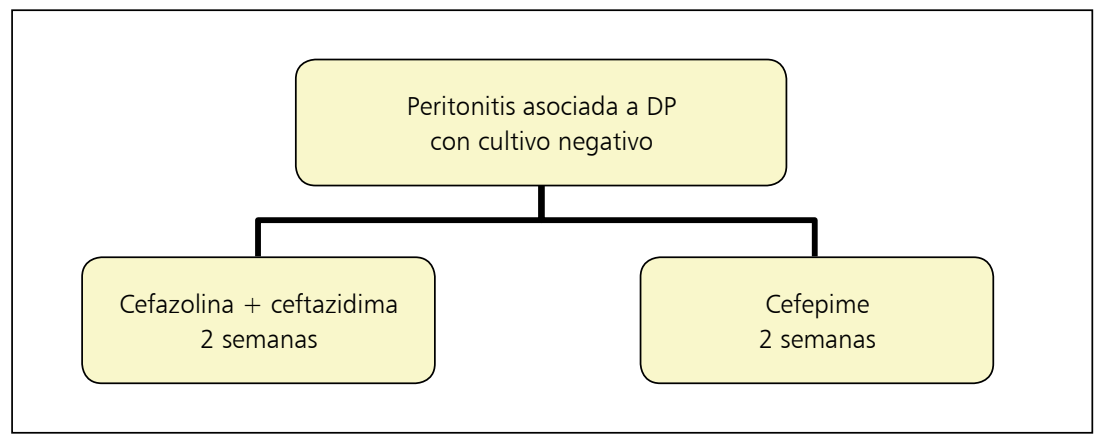

Algoritmo 3. Esquema antimicrobiano en peritonitis asociada a DP con cultivo negativo.
- Se recomienda la terapia continua de $\beta$-lactámicos ${ }^{26}$.

- Se recomienda no administrar en forma conjunta aminoglucósidos y penicilinas, ya que podrían inactivarse.

- Si se requiere el uso de terapias combinadas, se pueden mezclar vancomicina, cefalosporina y aminoglucósidos en misma solución de diálisis, ya que resultan compatibles y no se ha demostrado pérdida de su bioactividad $^{21}$.

- Existen datos limitados respecto a la farmacocinética y farmacodinamia en terapia intermitente de ciclos cortos.

\section{Terapia adyuvante}

- Para el alivio del dolor abdominal, efectuar inicialmente baños de entrada y salida de líquido de diálisis a volúmenes bajos ${ }^{19,22}$.

- En pacientes con disconfort abdominal, reducir el volumen de llenado durante las primeras 24 a $48 \mathrm{~h}$ de terapia.

- En caso de fibrina en el líquido drenado, usar heparina intraperitoneal $500 \mathrm{UI} / \mathrm{L}$ para prevenir la oclusión del catéter, hasta que el líquido se aclare.

- En pacientes con peritonitis refractaria o con hipogamaglobulinemia en el contexto de peritonitis o sepsis, prescribir inmunoglobulina intravenosa ${ }^{16}$. 


\section{Respuesta a tratamiento}

Se evalúa inicialmente con la inspección de las características macroscópicas del efluente, evidenciándose una reducción en su turbidez. En segundo lugar, una mejoría clínica del paciente, basado en la desaparición de la sintomatología y de la curva febril.

Se han diseñado scores clínicos, siendo el recomendado el "Disease Severity Score" (DSS) (Tabla 3), el que se aplica a las $72 \mathrm{~h}$ de iniciada la terapia. Un puntaje $<2$, se ha correlacionado con un buen resultado clínico ${ }^{16,27}$.

Si a las $72 \mathrm{~h}$ de iniciado el tratamiento antibacteriano no hay mejoría clínica, se debe repetir el recuento celular diferencial de efluente y cultivo de LP. Recuentos de leucocitos en LP $>1.090 / \mathrm{mm}^{3}$ en el día 3, se han asociado como factor independiente a falla al tratamiento. Además, deben buscarse fuentes potenciales de persistencia de la infección, y ante cultivos negativos, sospechar agentes de crecimiento lento, por lo que se recomienda adicionar estudio para hongos, micobacterias y realizar un subcultivo en medio aeróbico, anaerobio y microaerofílico para agentes fastidiosos que no se detectarán en cultivos tradicionales $^{18,19}$.

\section{Recurrencias de una peritonitis}

Pueden deberse a:

- Recaída de una peritonitis asociada a PD

Se define como el episodio que ocurre en menos de cuatro semanas de finalizado el tratamiento del episodio previo, debido al mismo agente. Ocurre aproximadamente en 10 a $20 \%$ de las peritonitis primarias ${ }^{2}$. Los factores de riesgo para presentar una recaída son: menor edad, catéter con cuffúnico y la exposición a profilaxis antimicrobiana crónica ${ }^{2}$.

Se asocia a una recuperación incompleta funcional del peritoneo y a una falla permanente en la técnica de $\mathrm{PD}^{22,23}$.

Son causadas en $46 \%$ por cocáceas grampositivas, $21 \%$ por bacilos gramnegativos y según el centro, hasta un tercio tienen cultivos negativos ${ }^{2}$.

Es importante considerar, que los episodios de recaída, no se cuentan como un episodio adicional, cuando se calculan las tasas de peritonitis vs episodios de recurrencia $\mathrm{y}$ repetición, en que sí deben ser considerados ${ }^{16}$.

\section{- Repetición de una peritonitis asociada a PD}

Es el episodio que ocurre más de 30 días después de completar la terapia del episodio previo, con mismo agente.El concepto de peritonitis a repetición fue acuñado a partir del año 2005; antes de esto, se pensaba que era una forma de recaída ${ }^{2}$.

Estudios recientes realizados en seguimiento entre los años 1999 y 2009 en un grupo de 181 pacientes con peritonitis a repetición, se identificaron 91 recaídas, describiéndose en éstas, agentes infecciosos diferentes y respuesta terapéutica distinta ${ }^{23,24}$.

Respecto a los episodios de recaída y de repetición, se encuentra como factor predisponente el desarrollo de la biopelícula ${ }^{16,24,25}$.

Se utiliza el término de refractariedad cuando existe una falla en normalizar el LP luego de 5 días de tratamiento antimicrobiano ${ }^{16}$.

\section{Peritonitis fúngicas}

Es una entidad poco frecuente en la edad pediátrica, representando menos de $2 \%$ todos los episodios de peritonitis ${ }^{20}$ y en niños la incidencia va de 4 a $10 \%{ }^{16}$. El agente más frecuentemente aislado es Candida sp.

La mayoría de estos episodios han sido precedidos por peritonitis bacterianas recurrentes y terapias antibacterianas previas ${ }^{16,20}$.

La llegada de los agentes antifúngicos al líquido peritoneal es variable. El fármaco de elección es fluconazol, administrado por vía iv, en dosis de 6 a $12 \mathrm{mg} / \mathrm{kg} /$ día, por su adecuada biodisponibilidad y penetración peritoneal, ajustándose luego según antifungigrama. Debe iniciarse precozmente y ha de retirarse el catéter de PD (en menos de $24 \mathrm{~h})^{20,21}$. La indicación de retiro se basa en la capacidad de Candida sp. de desarrollar una biopelícula. Los pacientes en que se retira precozmente el catéter tienen menor riesgo de recaída y de fallecer por esta causa ${ }^{27-29}$.

La duración del tratamiento recomendado es de dos semanas después de retirar el catéter y con resolución clínica de los síntomas ${ }^{16,18,21}$.

\section{Indicaciones de retiro del catéter de DP}

La remoción del catéter de DP pretende prevenir la morbimortalidad asociada a la peritonitis y preservar

\begin{tabular}{ll}
$\begin{array}{l}\text { Tabla 3. Score de gravedad de enfermedad en infecciones asociadas a diálisis } \\
\text { peritoneal "DSS" }\end{array}$ \\
\hline Síntoma y signo & Cuantía \\
$\begin{array}{ll}\text { Dolor } & \text { No } \\
0 & \text { Dolor moderado o náuseas que no requiere tratamiento específico } \\
1 & \text { Dolor intenso que requiere analgesia o vómitos } \\
2 & \text { Dolor peritoneal con abdomen tenso o íleo intestinal } \\
3 & \\
\text { Fiebre } & <37,5^{\circ} \mathrm{C} \\
0 & 37,5-38,9^{\circ} \mathrm{C} \\
1 & >38,9^{\circ} \mathrm{C} \\
2 & \end{array}$ \\
\hline
\end{tabular}

Total 0-5 suma de puntos de ambos ítems. Adaptado de referencia ${ }^{14,27}$ 
la MP. Pese a lo anterior, no existen estudios aleatorios controlados que evalúen las indicaciones y el tiempo oportuno para el retiro del dispositivo y tampoco del tiempo óptimo para la reinstalación de catéter.

Según las guías de IPSD el retiro del catéter peritoneal está indicado en las siguientes situaciones ${ }^{18,21}$ : peritonitis refractaria, peritonitis fúngica, infección del sitio de salida o tunelitis asociada a peritonitis por el mismo agente (excepto SCN) e infección del sitio de salida o tunelitis refractaria.

En términos generales, se recomienda un mínimo de 2-3 semanas de tratamiento antes de reinstalar catéter en caso de peritonitis fúngica y refractaria. Transitoriamente el paciente cambia de modalidad dialítica, a hemodiáli$\operatorname{sis}^{3,18,21}$

\section{Infecciones localizadas}

Infección del sitio de salida y tunelitis. Su presencia conlleva dos veces más riesgo de desarrollar peritonitis y tres veces más riesgo de requerir hospitalización por esta complicación infecciosa. Las bacterias que con mayor frecuencia las causan son: S. aureus, Pseudomonas spp, Enterococcus spp, E. coli, Klebsiella spp y otros bacilos gramnegativos.

Cabe mencionar que un cultivo positivo en ausencia de signos locales no es sinónimo de infección, sino más bien de colonización ${ }^{3,16,18}$.

\begin{tabular}{lccc}
\hline \multicolumn{4}{l}{ Tabla 4. Score para cuantificar la infección del sitio de salida } \\
\hline Signo & $\mathbf{0}$ & $\mathbf{1}$ & $\mathbf{2}$ \\
Tumefacción & No & Sólo sitio salida $(<0,5 \mathrm{~cm})$ & Incluye parte o todo túnel \\
Costra & No & $<0,5 \mathrm{~cm}$ & $>0,5 \mathrm{~cm}$ \\
Eritema & No & $<0,5 \mathrm{~cm}$ & $>0,5 \mathrm{~cm}$ \\
Dolor en presión & No & Leve & Intenso \\
Secreción & No & Seroso & Purulento \\
\hline Adaptado de referencia ${ }^{27}$. & & \\
\hline
\end{tabular}

Tabla 5. Antibióticos orales recomendados para tratamiento de infección orificio de salida y tunelitis

\begin{tabular}{lccc}
\hline Antibiótico & \multicolumn{1}{c}{$\begin{array}{c}\text { Dosis } \\
\text { recomendada }\end{array}$} & $\begin{array}{c}\text { Frecuencia de } \\
\text { administración }\end{array}$ & $\begin{array}{c}\text { Dosis máxima } \\
\text { por dosis }\end{array}$ \\
Flucloxacilina & $15 \mathrm{mg} / \mathrm{kg} /$ dosis & Cada $24 \mathrm{~h}$ & $250 \mathrm{mg}$ \\
Amoxicilina & $10-20 \mathrm{mg} / \mathrm{kg} /$ dosis & Cada $24 \mathrm{~h}$ & $1.000 \mathrm{mg}$ \\
Ciprofloxacina & $10-15 \mathrm{mg} / \mathrm{kg} /$ dosis & Cada $24 \mathrm{~h}$ & $500 \mathrm{mg}$ \\
Cotrimoxazol (en base a TMT) & $5-10 \mathrm{mg} / \mathrm{kg} /$ dosis & Cada $24 \mathrm{~h}$ & $80 \mathrm{mg}$ \\
\hline Adaptado de referencia ${ }^{14,18}$. & & & \\
\hline
\end{tabular}

\section{Infección del sitio de salida}

$\mathrm{Su}$ diagnóstico se fundamenta en la presencia de signos locales como tumefacción, eritema y sensibilidad peri-catéter. Se ha establecido el uso de un score, para unificar el criterio clínico (Tabla 4). Debe considerarse diagnóstico, si el puntaje es $>2$ con agente infeccioso demostrado o con puntaje $>4$ con cultivo negativo o pendiente.

En cuanto al tratamiento de la infección del sitio de salida, se recomienda, en general, antibioterapia oral por un mínimo de dos semanas, con al menos siete días desde la resolución de los signos inflamatorios. Si la infección es causada por $S$. aureus o Pseudomonas spp, se recomienda tratar por tres semanas. En caso de cocáceas grampositivas, usar cefalosporinas de primera generación; si es un bacilo gramnegativo utilizar cobertura para Pseudomonas, como ciprofloxacina oral. Si el cultivo es negativo o en espera del resultado y existen signos de gravedad iniciar empíricamente una cefalosporina de primera generación o ciprofloxacina ${ }^{6}$ (Tabla 5).

\section{Tunelitis o infección del túnel}

Definida como la presencia de eritema, edema o sensibilidad sobre el túnel subcutáneo, con o sin secreción purulenta desde el sitio de salida. Se puede utilizar el mismo score (Tabla 4) requiriendo un puntaje mayor a 6 para plantear el diagnóstico ${ }^{16}$. Se recomienda realizar una ecografía de tejidos blandos, en búsqueda de un área hipoecogénica sugerente de colección ${ }^{12}$.

La etiología es similar a la observada en la infección de sitio de salida y debe iniciarse terapia antimicrobiana oral empírica a la brevedad con una duración de 2 a 4 semanas (Tabla 5). Si no se observa mejoría clínica, tiene indicación de tratamiento antibacteriano i.v y considerar el cambio de catéter ${ }^{16,18}$.

Como terapia coadyuvante en la infección de túnel se recomienda la curación con solución salina fisiológica estéril del sitio de salida (una a dos veces/día), mientras exista secreción. El orificio de salida debe mantenerse seco. Deben removerse las costras, si existen, e indicar el uso tópico de nitrato de plata, en caso de presencia de un granuloma. Debe asegurarse la fijación del catéter y protegerlo de traumas ${ }^{3,18}$.

\section{Prevención de las complicaciones infecciosas asociadas a DP}

En relación a las medidas para la prevención de infecciones asociadas a DP se deben reconocer los factores de riesgo modificables y realizar un adecuado adiestramiento para la realización de la técnica, tanto en el hospital como ambulatoria, y una selección estricta de los pacientes candidatos a esta técnica de reemplazo renal ${ }^{12}$. 


\section{Recomendaciones}

- Inserción de catéter con técnica estéril, adecuada preparación de la piel y una dosis de antimicrobiano iv al momento de instalación, siendo más recomendado emplear una cefalosporina de $1^{\mathrm{a}}$ generación ${ }^{23}$.

- Equipo médico y de enfermería altamente calificado en la técnica de DP, con un programa de educación riguroso para la capacitación del niño y su familia.

- Tipo de catéter: uso de catéter Tenckhoff con doble cuff con túnel en cuello de cisne y con salida dirigida hacia abajo versus recta. En relación a la colocación del catéter, resulta de vital importancia determinar el sitio de salida. La inserción laparoscópica vs abierta no ha demostrado diferencias en un estudio único retrospectivo pediátrico y en dos estudios prospectivos en adultos ${ }^{12}$.

- Ubicación del sitio de salida debe definirse antes de la intervención quirúrgica y el orificio de salida debe ser colocado lejos de la línea de la cintura, de los pañales y de ostomas (gastrostomía, ureterostomía). Aunque no hay diferencia en el riesgo de peritonitis y ISS o infección del túnel, se prefiere en lactantes y niños una incisión fascial paramedial, para así evitar el riesgo de hernia o fugas del dializado que pueden predisponer a complicaciones infecciosas ${ }^{11}$.

- Posición del cuff exterior: éste debe ser situado a 2 $\mathrm{cm}$ del sitio de salida para disminuir la probabilidad de extrusión del cuff, una complicación asociada con un mayor riesgo de ISS.

- Profilaxis antibacteriana en la inserción del catéter: de acuerdo a las guías europeas, la recomendación es el uso único de una cefalosporina de primera generación como cefazolina iv, hasta $30 \mathrm{~min}$ antes del procedimiento. Vancomicina se debe utilizar sólo en centros con alta tasa de SARM (igual o mayor a $10 \%$ de los aislados de $S$. aureus causantes de IAAS) o en caso de alergia a $\beta$-lactámicos ${ }^{16,25}$.

- Profilaxis antifúngica: debe evaluarse la utilización de profilaxis antifúngica según la epidemiología local de cada centro ${ }^{27}$. Considerar su uso en centros con alta tasa de peritonitis fúngica. Se puede emplear nistatina o fluconazol oral ${ }^{10,27}$.

- Otras de las medidas preventivas a considerar son: el cuidado del orificio de salida, evitar traumas abdominales, baño diario, drenaje del líquido previo a la infusión de líquido peritoneal, mejoras en la técnica de conectología, uso de soluciones de diálisis más biocompatibles, entre otras ${ }^{16,18}$.

\section{Pronóstico}

La mayoría de los pacientes son exitosamente tratados alcanzando $89 \%$ de curación según registros internacionales y pueden continuar en DP. Un episodio único de peritonitis, en general, no produce un efecto significativo en la función peritoneal, aunque ya se ha descrito cambios tras el primer episodio de peritonitis ${ }^{30}$. La recurrencia de los eventos lleva a una disminución en la capacidad de depuración y ultrafiltración ${ }^{16}$. Es así como, la peritonitis sigue siendo la razón primaria de la falla de la técnica dialítica $^{19}$, pudiendo ocasionar en su máxima expresión de daño, una peritonitis esclerosante capsulada ${ }^{16}$.

Se ha estimado que $18 \%$ de los episodios resultan en una remoción del catéter peritoneal ${ }^{16}$, además por cada 0,5 episodio/año de incremento en la tasa de peritonitis, el riesgo de muerte aumenta en $4 \%$, siendo la tasa de mortalidad en niños de $1 \%{ }^{19}$. Presentan un pobre resultado final los pacientes con peritonitis por bacilos gramnegativos, las peritonitis fúngicas y las infecciones recurrentes ${ }^{18}$.

La mejor estrategia para lograr disminuir el impacto de las complicaciones infecciosas asociadas a DP, se basa en observar la serie de medidas preventivas antes descritas, dentro de la cuales, un programa intensivo de entrenamiento de la técnica dialítica a los familiares a cargo de la terapia y la evaluación de las condiciones domiciliarias del niño y su familia, son fundamentales.

Agradecimientos: Las autoras agradecen a Francisco Cano, Nefrólogo Infantil, encargado del Programa de Diálisis Peritoneal Crónica del Hospital Luis Calvo Mackenna y a José Cofré, Pediatra Infectólogo de la misma institución, por su valiosa colaboración en esta revisión.

\section{Resumen}

Las infecciones asociadas a diálisis peritoneal (DP), corresponden a la principal complicación de los pacientes pediátricos en esta terapia de reemplazo renal, disminuyendo la sobrevida de la membrana peritoneal y empeorando el pronóstico del paciente. El reconocimiento precoz y un tratamiento oportuno de éstas son fundamentales para preservar esta modalidad dialítica. Se presenta una revisión actualizada de la literatura científica, con el fin de entregar recomendaciones reproducibles en los distintos centros pediátricos que realizan diálisis peritoneal crónica en niños. 


\section{Referencias bibliográficas}

1.- Graevenitz AVON, Amsterdam D. Microbiological aspects of peritonitis associated with continuous ambulatory peritoneal dialysis. Clin Microbiol Rev 1992; 5 (1): 36-48.

2.- Bakkaloglu S A, Warady B A. Difficult peritonitis cases in children undergoing chronic peritoneal dialysis: relapsing, repeat, recurrent and zoonotic episodes. Pediatr Nephrol 2014; 30 (9): 1397-406. doi: 10.1007/s00467-0142952-y. Epub 2014 Sep 18.

3.- Barrera P, Zambrano P, Contreras A, Dreves P, Salgado I, Vogel A, et al. Complicaciones infecciosas en diálisis peritoneal crónica. Rev Chil Pediatr 2008; 79 (5): 522-36.

4.- Delucchi A, Contreras M, Bidegain A, Quiero X, Barrera P, Pinto V, et al. Diálisis peritoneal crónica pediátrica en Chile. Estudio multicéntrico. Rev Chil Pediatr 2002; 73 (2): 116-26.

5.- Saxena R. Pathogenesis and treatment of peritoneal membrane failure. Pediatr Nephrol 2008; 23 (5): 695-703.

6.- Yung S, Chan T M. Pathophysiological changes to the peritoneal membrane during PD-related peritonitis: The role of mesothelial cells. Mediators Inflamm 2012. http://dx. doi. org/10.1155/2012/484167.

7.- North American Pediatric Renal Trials and Collaborative Studies (NAPRTCS) 2011 annual dialysis report p. 295-306. Disponible en: http://www.usrds.org/2013/pdf/v2_ch8_13.pdf (accedido el 01 de julio de 2017).

8.- Pulliam J, Li N-C, Maddux F, Hakim R, Finkelstein FO, Lacson E. First-year outcomes of incident peritoneal dialysis patients in the United States. Am J Kidney Dis 2014; 64 (5): 761-9. doi: 10.1053/j.ajkd.2014.04.025. Epub 2014 Jun 11.

9.- Kerschbaum J, König P, Rudnicki M. Risk factors associated with peritonealdialysisrelated peritonitis. Int J Nephrol 2012; 2012. http://dx.doi.org/10.1155/2012/483250.

10.- Campbell D J, Johnson D W, Mudge D W, Gallagher M P, Craig J C. Prevention of peritoneal dialysis-related infections. Nephrol Dial Transplant. 2015; 30(9): 1461-72. doi: 10.1093/ndt/gfu313. Epub 2014 Oct 7.

11.- Stewart C L, Acker S N, Pyle L L, Kulungowski A, Cadnapaphornchai M, Bruny
$\mathrm{J}$ L, et al. Factors associated with peritoneal dialysis catheter complications in children. J Pediatr Surg 2016; 51 (1): 159-62. doi: 10.1016/j.jpedsurg.2015.10.035. Epub 2015 Oct 21.

12.- Meza M J, García E, Mendoza L, Miranda M G, Solórzano F. Factores de riesgo de peritonitis recurrente en pacientes. Enf Inf Microbiol 2006; 26 (2): 46-51.

13.- López-González D, Garduno J, Reyes-López A, Partida-Gaytan A, Medeiros M. Risk factors associated with nosocomial peritonitis in children on peritoneal dialysis. Rev Invest Clin 2015; 67 (3): 170-6.

14.- Warady B, Schaefer F, Alexander S. Peritoneal access in children receiving dialysis. Second Ed. 2012; 2012. 153-168 p.

15.- Daugirdas J, Blake P, Ing T. Catéteres para diálisis peritoneal: colocación y cuidados. In Manual de Diálisis 2015. p. 425-50.

16.- Akoh J A. Peritoneal dialysis associated infections: An update on diagnosis and management. World J Nephrol 2012; 1 (4): 106-22. doi: 10.5527/wjn.v1.i4.106.

17.- Fieren MWJ a. Cloudy peritoneal dialysate: in search of a clear cause? J Am Soc Nephrol 2013; 24 (12): 1929-31. doi: 10.1681/ ASN.2013080911.

18.- Warady B A, Bakkaloglu S, Newland J, Cantwell M, Verrina E, Neu A, et al. Consensus guidelines for the prevention and treatment of catheter-related infections and peritonitis in pediatric patients receiving peritoneal dialysis: 2012 update. Perit Dial Int 2012; 32 Suppl 2. doi: 10.3747/pdi.2011.00091.

19.- Bieber S D, Anderson A E, Mehrotra R. Diagnostic testing for peritonitis in patients undergoing peritoneal dialysis. Semin Dial 2014; 27 (6): 602-6. doi: 10.1111/sdi.12270.

20.- Matuszkiewicz-Rowinska J. Update on fungal peritonitis and its treatment. Perit Dial Int 2009; 29 (Suppl. 2): 161-5.

21.- Li PKT, Szeto C C, Piraino B, de Arteaga J, Fan S, Figueiredo A E, et al. ISPD peritonitis recommendations: 2016 update on prevention and treatment. Perit Dial Int 2016; 36 (5): 481-508. doi: 10.3747/pdi.2016.00 van Diepen ATN, van Esch S, Struijk DG, Krediet RT.078. Epub 2016 Jun 9. doi: 10.1007/s00467-0081113-6. Epub 2009 Feb 4.

22.- Chadha V, Schaefer F S, Warady B A. Dialysisassociated peritonitis in children.
Pediatr Nephrol. 2010; 25 (3): 425-40. doi: 10.1007/s00467-008-1113-6. Epub 2009 Feb 4.

23.- Piraino B, Bernardini J, Brown E, Figueiredo A, Johnson D W, Lye W C, et al. ISPD position statement on reducing the risks of peritoneal dialysis-related infections. Perit Dial Int 2011; 31 (6): 614-30. doi: 10.3747/pdi.2011.00057. Epub 2011 Aug 31.

24.- Lane J C, Warady B A, Feneberg R, Majkowski N L, Watson A R, Fischbach M, et al. Relapsing peritonitis in children who undergo chronic peritoneal dialysis: A prospective study of the International Pediatric Peritonitis Registry. Clin J Am Soc Nephrol 2010; 5 (6): 1041-6. doi: 10.2215/ CJN.05150709. Epub 2010 Apr 29.

25.- Szeto C C, Kwan B C H, Chow K M, Law M C, Pang W F, Leung C B, et al. Repeat peritonitis in peritoneal dialysis: Retrospective review of 181 consecutive cases. Clin J Am Soc Nephrol 2011; 6 (4): 827-33. doi: 10.2215/CJN.05370610. Epub 2010 Dec 23.

26.- Schaefer F, Klaus G, Dirk E, MullerWiefel O M. Intermittent versus continuous intraperitoneal glycopeptide/ceftazidime treatment in children with peritoneal dialysisassociated peritonitis. J Am Soc Nephrol 1999; (6): 136-45.

27.- Walker A, Bannister K, George C, Mudge D, Yehia M, Lonergan M, et al. KHACARI guideline: Peritonitis treatment and prophylaxis. Nephrology 2014; 19 (2): 69-71. http://www. cari.org.au/Dialysis/dialysis\%20peritonitis/ Summaries/Walker_2014_69.pdf

28.- Martins M, Rodrigues A, Pedrosa J M, Carvalho M J, Cabrita A, Oliveira R. Update on the challenging role of biofilms in peritoneal dialysis. Biofouling 2013; 29: 1015-27. doi: 10.1080/08927014.2013.824566.

29.- Miles R, Hawley C M, McDonald S P, Brown F G, Rosman J B, Wiggins K J, et al. Predictors and outcomes of fungal peritonitis in peritoneal dialysis patients. Kidney Int 2009; 76 (6): 6228.

30.- van Diepen ATN, van Esch S, Struijk D G, Krediet R T. The first peritonitis episode alters the natural course of peritoneal membrane characteristics in peritoneal dialysis patients. Perit Dial Int 2015; 35 (3): 324-32. DOI: $10.3747 /$ pdi.2014.00277 